\title{
LAS REFORMAS DEL TLCUEM EN MATERIA DE PROPIEDAD INTELECTUAL
}

\section{THE REFORMS OF THE TLCUEM ON INTELLECTUAL PROPERTY MATTERS}

\author{
Salvador Francisco Ruiz Medrano ${ }^{1}$
}

\begin{abstract}
Los inicios de la negociación del TLCUEM en la década de los años noventa fueron complicados para México, y la negociación en materia de propiedad intelectual fue también compleja, puesto que bajo México ya planeaba la idea de ser un país poco respetuoso es estos derechos, por lo que integrarlo en una serie de actualizaciones de Tratados Internacionales sobre la materia se volvió una cuestión prioritaria. Sin embargo, al provocar estas actualizaciones, y ya entrando con las nuevas platicas de reformas del Acuerdo, mejor conocido como el TLCUEM, en donde la UE intento proteger determinados productos a través de indicaciones geográficas, cuestión que se analizará desde una perspectiva jurídica mexicana y de los tratados internacionales, le dio las herramientas necesarias para que la negociación no desembocase en un fracaso y le permitió a México cierto margen de ganancia al final de estas, sobre todo en la llamada por la prensa "Guerra de los quesos".
\end{abstract}

Palabras Clave: TLCUEM, Propiedad industrial, denominación de origen, guerra de quesos, derecho internacional público y privado.

\begin{abstract}
The beginnings of the negotiation of the TLCUEM in the decade of the nineties were complicated for Mexico, and the negotiation in the matter of intellectual property was also complex, since under Mexico already planned the idea of being a little respectful country these rights, for what to integrate it in a series of updates of International Treaties on the matter became a priority issue. However, by provoking these updates, and already entering with the new talks of reforms of the Agreement, better known as the FTA, where the EU tries to protect certain products through geographical indications, an issue that will be analyzed from a

${ }^{1}$ Es Doctor en Derecho Internacional Privado por la Universidad de Valencia, España, con especialidad en Propiedad Intelectual, DEA en Derecho Internacional Privado a través de la Universidad de Valencia y Licenciado en Derecho. En su carrera académica imparte clases de postgrado en la Maestría en Administración y en la Maestria en Fiscal de la Universidad de Guanajuato, en la materia de Derecho Corporativo y Taller de Tesis respectivamente. Su producción científica incluye diversos papers científicos en revistas arbitradas nacionales e internacionales Su producción incluye artículos, que se han publicado en México, Colombia, Chile y Bolivia. Diversos capítulos de libros que han sido publicados en México, Chile, y Colombia y dos libros. En el mundo académico es actualmente profesor de tiempo completo del Departamento de Gestión y Dirección de Empresas de la División de Ciencias Económico Administrativas de la Universidad de Guanajuato, donde imparte las materias de Contratos Internacionales, Comercio Electrónico y en el Departamento de Derecho de la misma universidad, la materia de Hermenéutica Jurídica. Su campo de la investigación se centra en la Propiedad Intelectual, aspectos actuales en México y el mundo. Universidad de Guanajuato - México. ORCID: https://orcid.org/0000-0002-81202274 Lattes: http://lattes.cnpq.br/9894300167305005 E-mail: salvador.rm@ugto.mx
\end{abstract}


Mexican legal perspective and of the international treaties, gave him the necessary tools so that the negotiation did not end in failure and allowed Mexico some margin of profit at the end of these, especially in the press call "War of the cheeses".

Keywords: TLCUEM, Industrial property, appellation of origin, cheese war, public and private international law.

\section{EL NACIMIENTO DEL TLCUEM.}

\subsection{Antecedentes, negociación y origen del TLCUEM.}

Como es fácilmente deducible, derivado del TLCAN, México tiene una dependencia muy fuerte, tanto de carácter económico como político, con Estados Unidos. El Gobierno sabiendo esto y en un intento de diversificar sus exportaciones, así como para intentar disminuir esta dependencia, se iniciaron los acercamientos necesarios para poder dar inicio a las pláticas de un acuerdo comercial con la Unión Europea. Dichos acercamientos, por parte de México a la Unión Europea, en materia comercial, puede decirse que nacen a partir de 1960, con el establecimiento de una misión mexicana en Bruselas ante la CEE.

En 1971 se llevan a cabo reuniones multilaterales CECLA²-CEE, en donde México participa y lleva a cabo varias entrevistas de alto nivel, entre otras, del presidente Luis Echeverría y el señor Francois Xavier Ortoli, presidente de la Comisión Europea, en abril de 1973, lo que motivó posteriores reuniones de trabajo, culminando en junio de 1974 con el Acuerdo de Cooperación entre dichas partes para “...ampliar su cooperación comercial y económica...", publicado en el Diario Oficial del 11 de febrero de 1976 (Cruz Miramontes, 2003, pág. 160).

Este acuerdo perduró poco más de quince años, y fue sustituido por el Acuerdo Marco de Cooperación, firmado en Luxemburgo el 26 de abril de 1991, y según como se puede calificar es de tercera generación, pues es mucho más ambicioso, ya que abarca temas no sólo comerciales, sino va más allá, pues se refiere a la cooperación económica, tecnológica, agricultura, medio ambiente, comunicaciones y otros más (Cruz Miramontes, 2003, pág. 160). En este contexto era importante la participación europea para el gobierno mexicano, aunque los

${ }^{2}$ Comisión Especial de Coordinación Latino Americana, instrumento que reunía a los ministros de relaciones exteriores de los países latinoamericanos, y que, en 1975 es remplazado por el actual SELA, (Sistema Económico Latinoamericano). 
tiempos políticos no correspondieran a los tiempos económicos y el acercamiento a Estados Unidos fuera mucho más rápido y espectacular que el acercamiento a Europa. De esta manera, apenas se concretó la nueva alianza con Estados Unidos y Canadá, el gobierno mexicano se abocó a la conclusión de una alianza estratégica con Europa (Sberro, 2004, pág. 132).

Desde los inicios de la entrada en vigor del Tratado de Libre Comercio de América del Norte, México comenzó a mirar hacia Europa con la finalidad de romper, o por lo menos disminuir, la dependencia del mercado estadounidense, derivado de esto se puede entender la negociación, firma y entrada en vigor de este Tratado. Sin embargo, los comienzos de esto no fueron sencillos, puesto que en el seno de la UE había en 1997 un ambiente de apatía hacia México. Bajo el título "Hacia una nueva etapa en las relaciones Unión Europea/América Latina: un diagnóstico inicial", el informe, elaborado por el antiguo director jurídico del Consejo de Ministros, Ramón Torrent, ofrece un testimonio de primera mano sobre las grandes dificultades que enfrentó México para que la UE lo aceptara como "socio comercial". El informe sostiene que, con la excepción de España y Alemania, los otros 13 socios europeos de la época "no manifestaban el más mínimo interés" por profundizar la relación con los mexicanos (Appel, 2005).

En este contexto, el Consejo de Ministros no quería ceder más que una fórmula menor de diálogo en donde se puede decir incluso que estaban dispuestos a que las primeras negociaciones naufragaran por una discrepancia, que puede ser calificada de absolutamente menor y de pura retórica, en la redacción de la llamada cláusula democrática. Las capitales comunitarias esperaron sin éxito que el entonces gobierno del presidente Ernesto Zedillo reaccionara como el australiano, que abortó las pláticas al rechazar ese condicionamiento. Sin embargo, si el gobierno mexicano pudo cumplir esta meta, se debió al decisivo apoyo del gobierno español y al cabildeo que desplegaron sus funcionarios en Bruselas, la cual estaba envuelta en una ola de acuerdos con todo mundo (Peña \& Torrent, 2005, págs. 30-31, 42-45).

Sin embargo, no fue sino hasta el 6 de junio del año 2000 cuando se aprobaron por el Senado de la República por parte de México, los textos del llamado Acuerdo Global y las Decisiones de los Consejos Conjuntos establecidos conforme al Acuerdo de Asociación Económica, Concertación Política y Cooperación, así como del Acuerdo Interino sobre Comercio y cuestiones relacionadas con el Comercio entre los Estados Unidos Mexicanos, por 
una parte, y la Comunidad Europea y sus Estados miembros, por la otra ${ }^{3}$; el cual entró en vigor el 1 de julio de 2000. De esta forma, en los considerandos se ratifican la herencia cultural común, los vínculos históricos, políticos y económicos, así como también se pretende desarrollar y consolidar el marco global de las relaciones internacionales entre, no sólo México, sino también América Latina y Europa ${ }^{4}$.

Sin embargo, este Acuerdo no consta en un sólo documento, pues de sus disposiciones se desprende, que su aplicación, conlleva a la consideración de dos documentos más a saber: 1) la Decisión del Consejo Conjunto de dicho Acuerdo; y, 2) la Decisión del Consejo Conjunto del Acuerdo Interno sobre Comercio y Cuestiones relacionadas con el comercio entre México y la Comunidad Europea (Decisión número 2/2000 del Consejo Conjunto).

Ambos ordenamientos, tanto el Acuerdo como las Decisiones del Consejo Conjunto, fueron aprobados por el Senado de la República mediante decreto publicado en el DOF del 2 de junio de 2000, y promulgados el 26 de junio del mismo año (Witker \& Hernández, Régimen Jurídico del comercio exterior de México, 2002, pág. 228).

El objetivo principal del Acuerdo es el establecimiento de un marco que fomente el desarrollo de los intercambios comerciales de bienes y servicios. Siendo el Consejo Conjunto, el encargado de decidir las medidas y el calendario para la liberación bilateral, progresiva y recíproca de las barreras arancelarias y no arancelarias, tanto de bienes como de servicios. Atendiendo a lo establecido en los acuerdos multilaterales de la OMC, en especial al artículo XXIV del Acuerdo General de Aranceles Aduaneros y Comercio de 1994, y al artículo V del Acuerdo General sobre el Comercio de Servicios (Witker \& Hernández, Régimen Jurídico del comercio exterior de México, 2002, pág. 229).

\subsection{Los Alcances del TLCUEM.}

En virtud de las características y estructura tan particular de la Unión Europea, ha formado una arquitectura muy rica y compleja, en cuanto modelo de integración y cooperación internacional, que contagia a otros países a través de los acuerdos que realiza. Esto ha dado

\footnotetext{
${ }^{3}$ Preámbulo, publicado en el Diario Oficial de la Federación, 26 de junio del 2000, p. 1.

${ }^{4}$ Considerandos 1 y 2 del Acuerdo de Asociación Económica, Concertación Política y Cooperación entre los Estados Unidos Mexicanos, por una parte, y la Comunidad Europea y sus Estados Miembros, por otra, publicado en el Diario Oficial de la Federación, 26 de junio de 2000, p. 2.
} 
lugar a que el acuerdo firmado con México sea tan particular y poco tenga en común con otros Tratados.

Estas particularidades se observan desde la denominación del acto celebrado, “Acuerdo de Asociación Económica, Concertación Política y Cooperación... ”, por tanto, es:

1) Un acuerdo de asociación económica, porque comprende aspectos relativos al comercio de bienes y servicios, movimientos de capitales, contratación pública, competencia, propiedad intelectual y finanzas (Mansilla y Mejía, 2001, pág. 123). Para alcanzar esto, el tratado se integra por diversos instrumentos jurídicos que complementariamente tuvieron que ser firmados para dar avances graduales en la puesta en marcha de sus objetivos (Aranda Godoy, 2001, pág. 97). En este sentido, se adopta el Acuerdo Global como instrumento que incluye todas las disciplinas materia de la liberalización, pero también un Acuerdo Interino que sirve de vertiente para iniciar la liberalización comercial que el propio Acuerdo Global dispone, y al mismo tiempo una Declaración Conjunta que comprometerá a las partes a negociar el resto de las disciplinas y evitar que los intereses se concentren únicamente en la parte comercial (Aranda Godoy, 2001, pág. 99).

2) Existe concertación política, porque regula aspectos relativos a refugiados, Derechos Humanos y democracia a través de la Cláusula de Dialogo Político.

3) Hay cooperación, ya que ha sido acordada en veinticuatro aspectos dentro de los cuales destacan: salud, pobreza, educación, explotación de recursos naturales, cultura, ciencia y tecnología, por nombrar tan sólo los más relevantes.

De esta manera queda claro que este Acuerdo, rebasa con creces los límites de un tratado comercial, que únicamente busca romper las barreras técnicas al comercio, tal y como lo pueda ser el TLCAN. Así, México firmó no únicamente un Tratado de Libre Comercio, ya que los elementos que abarca no son únicamente comerciales, sino también, aspectos de carácter social y cooperación.

\subsection{Los Objetivos del Acuerdo.}

En los objetivos principales del TLCUEM está el crear procedimientos eficaces para la aplicación y cumplimiento del Tratado para su administración conjunta y para solución de controversias, y sin lugar a duda, el carácter de las competencias compartidas entre la Comunidad y los Estados miembros de la Unión Europea guarda un especial trato para tener 
presente, y desde un ámbito comunitario o bien dentro de la arquitectura del propio TLCUEM, la forma en que es abordado el tema de la solución de controversias (Aranda Godoy, 2001, pág. 115). En un sentido más amplio, se cuenta como objetivos el de desarrollar y consolidar el marco global de las relaciones internacionales, en particular entre América Latina y Europa, así como también el de establecer un marco para fomentar el desarrollo de los intercambios de bienes y servicios, incluyendo una liberalización bilateral y preferencial, progresiva y recíproca del comercio de bienes y servicios; para lo que se decidirá las medidas necesarias para la liberalización progresiva y recíproca del comercio de servicios teniendo debidamente en cuenta los compromisos adquiridos por cada una de las Partes en el marco de dicho Acuerdo.

\section{LA PROTECCIÓN DE LA PROPIEDAD INTELECTUAL EN EL MARCO DEL TLCUEM.}

\subsection{Antecedentes.}

Es en el Título $\mathrm{V}$, en donde encontramos el tratamiento que se dará a la propiedad intelectual en el marco de este Acuerdo, el cual se denomina: Contratación Pública, Competencia, Propiedad Intelectual y Demás Disposiciones Relacionadas con el Comercio. Así, el trato que deciden las partes darle a la propiedad intelectual e industrial dentro del Acuerdo, inicia, primeramente, en la decisión de someter la regulación de la materia a diversas convenciones multilaterales sobre propiedad intelectual. El margen que aquí se deja a los acuerdos mixtos es muy reducido por no decir prácticamente nulo, toda vez que existe el sometimiento expreso, ya no a legislaciones nacionales, sino a normas de carácter internacional (Aranda Godoy, 2001, pág. 110).

La definición que se da en el mismo Acuerdo de la propiedad intelectual, la encontramos en el artículo 12.1 donde se aplica una definición amplísima de los elementos que han de protegerse de las propiedades especiales, así se protegerán los "derechos de autor, incluidos los derechos de autor en los programas de computación y las bases de datos, y los derechos conexos, los derechos relacionados con patentes, diseños industriales, indicaciones geográficas, incluidas las denominaciones de origen, marcas, topografías de circuitos integrados, así como la protección contra la competencia desleal tal como se define en el 
artículo 10 bis del Convenio de París ${ }^{5}$ sobre la Protección de la Propiedad Industrial y la protección de la información confidencial ${ }^{6}$." Como se puede observar, el TLCUEM incluye los programas de computadoras en la propiedad intelectual, así como también incluyen aspectos, tanto de derechos de autor como de propiedad industrial, lo que en ocasiones resulta un poco confuso.

Para lograr esta protección, se ha establecido que el Consejo Conjunto decidirá: 1) un mecanismo de consultas con miras a alcanzar soluciones mutuamente satisfactorias en caso de dificultades en la protección de la propiedad intelectual; 2) las medidas específicas que deberán adoptarse para alcanzar los objetivos antes establecidos, tomando en cuenta, en particular, las convenciones multilaterales relevantes sobre propiedad intelectual ${ }^{7}$. Así, tenemos un gran avance por lo que respecta al TLCAN en esta materia, ya que aquí se impone un sistema, especializado de resolución de controversias.

\subsubsection{Los acuerdos internacionales sobre la materia que debió firmar México.}

Es en la Decisión No --/---- del Consejo Conjunto (sic) donde encontramos el fundamento jurídico de estos mecanismos de solución de controversias. Esta decisión fue firmada en las ciudades de Bruselas y Lisboa, los días veintitrés y veinticuatro de febrero de dos mil, respectivamente, e incluida en el texto oficial del TLCUEM, la cual tras una serie de considerandos, indica en su Título I, Artículo 1 que el Consejo Conjunto establece los acuerdos necesarios para alcanzar los objetivos siguientes del Acuerdo: (a) la liberalización progresiva y

${ }^{5}$ Artículo 10 Bis del Convenio de París: “1) Se reserva a las legislaciones de los países de la Unión la facultad de permitir la reproducción por la prensa o la radiodifusión o la transmisión por hilo al público de los artículos de actualidad de discusión económica, política o religiosa publicados en periódicos o colecciones periódicas, $u$ obras radiodifundidas que tengan el mismo carácter, en los casos en que la reproducción, la radiodifusión o la expresada transmisión no se hayan reservado expresamente. Sin embargo, habrá que indicar siempre claramente la fuente; la sanción al incumplimiento de esta obligación será determinada por la legislación del país en el que se reclame la protección. 2) Queda igualmente reservada a las legislaciones de los países de la Unión la facultad de establecer las condiciones en que, con ocasión de las informaciones relativas a acontecimientos de actualidad por medio de la fotografía o de la cinematografía, o por radiodifusión o transmisión por hilo al público, puedan ser reproducidas y hechas accesibles al público, en la medida justificada por el fin de la información, las obras literarias o artísticas que hayan de ser vistas u oidas en el curso del acontecimiento”.

${ }^{6}$ Vid. Artículo 12.1 del Título V del Acuerdo de Asociación Económica, Concertación Política y Cooperación entre los Estados Unidos Mexicanos, por una parte, y la Comunidad Europea y sus Estados Miembros, por otra, publicado en el Diario Oficial de la Federación, 26 de junio de 2000, p. 5.

${ }^{7}$ Vid. Artículo 12.2 del Título V del Acuerdo de Asociación Económica, Concertación Política y Cooperación entre los Estados Unidos Mexicanos, por una parte, y la Comunidad Europea y sus Estados Miembros, por otra, publicado en el Diario Oficial de la Federación, 26 de junio de 2000, p. 5. 
recíproca del comercio de servicios, de conformidad con el artículo V del $\mathrm{AGCS}^{8}$; (b) la liberalización progresiva de la inversión y pagos; (c) asegurar la protección adecuada y efectiva de los derechos de propiedad intelectual, de conformidad con las normas internacionales más exigentes; y (d) el establecimiento de un mecanismo de solución de controversias ${ }^{9}$.

En el Título IV, en su artículo 36 es donde se establecen las convenciones multilaterales sobre propiedad intelectual que forman parte de México y de la Unión Europea, por tanto, las que regirán en el Acuerdo, así confirman sus obligaciones derivadas de las siguientes convenciones multilaterales: a) el Acuerdo sobre los Aspectos de los Derechos de Propiedad Intelectual relacionados con el Comercio (Acuerdo sobre los ADPIC, 1994); b) el Convenio de París para la Protección de la Propiedad Industrial (Acta de Estocolmo, 1967); c) el Convenio de Berna para la Protección de las Obras Literarias y Artísticas (Acta de París, 1971); d) la Convención Internacional sobre las Protección de los Artistas Intérpretes o Ejecutantes, los Productores de Fonogramas y los Organismos de Radiodifusión (Roma, 1961); y e) el Tratado de Cooperación en Materia de Patentes (Washington 1970, enmendado en 1979 y modificado en 1984$)^{10}$.

En este mismo sentido, el mismo artículo en su segundo apartado ${ }^{11}$ hace un recordatorio de sus adhesiones a las convenciones UPOV 1 y UPOV 2, y en el apartado 3 señala que a la entrada en vigor de le decisión ${ }^{12}$, México y los Estados miembros de la Comunidad se habrán adherido al Arreglo de Niza relativo a la Clasificación Internacional de Productos y Servicios para el Registro de las Marcas (Ginebra 1977, y enmendado en 1979), en el apartado 4 se señala que dentro de los tres años siguientes la entrada en vigor de esta Decisión, México y los Estados Miembros de la Comunidad se habrán adherido al Tratado de Budapest sobre el Reconocimiento Internacional del depósito de microorganismos a los fines del procedimiento

\footnotetext{
${ }^{8}$ Acuerdo General sobre Comercio de Servicios.

${ }^{9}$ Artículo 1 del Título I - Disposiciones Generales de la Decisión No --/---- del Consejo Conjunto publicado en el Diario Oficial de la Federación, 26 de junio de 2000, p. 17.

${ }^{10}$ Artículo 36.1 del Título IV - Disposiciones Generales de la Decisión No --/---- del Consejo Conjunto publicado en el Diario Oficial de la Federación, 26 de junio de 2000, p. 27.

11 "2. Las Partes confirman la importancia que le otorgan a las obligaciones derivadas de la Convención Internacional para la Protección de las Obtenciones Vegetales, 1978 (Convención UPOV 1978), o la Convención Internacional para la Protección de las Obtenciones Vegetales, 1991 (Convención UPOV 1991). ”, Artículo 36.2 del Título IV - Disposiciones Generales de la Decisión No --/---- del Consejo Conjunto publicado en el Diario Oficial de la Federación, 26 de junio de 2000, p. 28.

${ }^{12} \mathrm{El}$ acuerdo entró en vigor el $1^{\circ}$ de julio de 2000 , es esta la fecha que se toma en consideración para indicar que la decisión entro en vigor.
} 
en materia de patentes (1977, modificado en 1980) ${ }^{13}$, y finalmente, en el apartado 5 se explica que las Partes harán todo su esfuerzo para completar, a la brevedad posible, los procedimientos necesarios para su adhesión a las siguientes convenciones multilaterales: (a) el Tratado de la Organización Mundial de la Propiedad Intelectual (OMPI) sobre Derecho de Autor (Ginebra, 1996); y (b) el Tratado de la OMPI sobre Interpretación o Ejecución y Fonogramas (Ginebra, 1996) $)^{14}$.

Las razones de dicha obligación de adhesión por parte de México a estos Convenios internacionales, aun y cuando ha de recordarse que ya se formaba parte de todos ellos por virtud de su adhesión años antes al TLCAN, con la excepción del Arreglo de Niza, el Tratado de Budapest, el Tratado de la Organización Mundial de la Propiedad Intelectual (OMPI) sobre Derecho de Autor y el Tratado de la OMPI sobre Interpretación o Ejecución y Fonogramas los cuáles los dos primeros entraron en vigor el 21 de marzo de 2001 y el 6 de marzo de 2002 y 20 de mayo de 2002 respectivamente, es principalmente para lograr una armonización de principios e instituciones jurídicas de las partes miembros del Acuerdo, así, la protección de derechos de propiedad intelectual se ajusta a las normas internacionales más estrictas (Cuenca García, 2002, págs. 153-154).

\subsection{Los cambios en materia de propiedad industrial que se incorporan de recientes negociaciones.}

El 14 de agosto de este año, la Secretaría de Economía lanzo una convocatoria a la que denomino Consulta sobre Indicaciones Geográficas en el marco de la Modernización del TLCUEM (Secretaría de Economía, 2017) la cual a la letra explicaba:

"En el marco de la Modernización del Pilar Comercial del "Acuerdo de Asociación Económica, Concertación Política y Cooperación entre la Comunidad Europea y sus Estados Miembros, por una parte y los Estados Unidos Mexicanos, por otra" (TLCUEM), se desarrolla la negociación de un capítulo de Propiedad Intelectual, en el cual se busca el reconocimiento y protección de Indicaciones Geográficas. Se entiende por "Indicación Geográfica" el nombre de una zona geográfica o que contenga dicho nombre, u otra indicación conocida por hacer referencia a la citada zona, que identifique un producto como originario de la

\footnotetext{
${ }^{13}$ Artículo 36.4 del Título IV - Disposiciones Generales de la Decisión No --/---- del Consejo Conjunto publicado en el Diario Oficial de la Federación, 26 de junio de 2000, p. 28.

${ }^{14}$ Artículo 36.5 del Título IV - Disposiciones Generales de la Decisión No --/---- del Consejo Conjunto publicado en el Diario Oficial de la Federación, 26 de junio de 2000, p. 28.
} 
misma, cuando determinada calidad, reputación u otra característica del producto sea imputable fundamentalmente a su origen geográfico."

La inclusión de las indicaciones geográficas en el GATT fue iniciativa de países de la Unión Europea donde el desarrollo de la agricultora está enormemente ligado a esta modalidad de Propiedad Intelectual. La Convención de París, originada en Europa, ya regulaba las indicaciones de procedencia o denominaciones de origen, como un elemento más susceptible de ser protegido a través de la propiedad industrial y establecía medidas de observancia del derecho para el caso de indicaciones falsas sobre la procedencia del producto (Abarza \& Katz, 2002, pág. 26). El Acuerdo de los ADPIC ${ }^{15}$ empiezan por definir qué se entiende por Indicación Geográfica y asimilan esta definición a lo que tradicionalmente se ha entendido por Denominación de Origen. Señala el artículo 22.1: “...las que identifiquen un producto como originario del territorio de un Miembro o de una región o localidad de ese territorio, cuando determinada calidad, reputación, u otra característica del producto sea imputable fundamentalmente a su origen geográfico.” (Abarza \& Katz, 2002, pág. 27)

Sin embargo, hay que considerar que de acuerdo con la Ley de la Propiedad Industrial del 27 de junio de 1991, con últimas modificaciones a fecha de hoy del 1 de junio de 2016, no se hace mención alguna a la figura de indicación geográfica, por lo que estamos ante una figura atípica que carece de un sustento de carácter formal en nuestro país, si bien se pudiese alegar en defensa de esto que si se encuentra la llamada Denominación de Origen, su sustento legal es diametralmente diferente puesto que este se encuentra dentro de lo que es el Acuerdo de Lisboa que data de 1958 y del que México es parte desde el 25 de septiembre de 1966, dónde se establecen criterios claros para considerar a un determinado producto como único y con la necesidad, de carácter administrativo, de un Consejo Regulador que sustente la característica de único del mismo ante cualquier otro competidor y no únicamente sobre la base del nombre de una zona, región o país, como es el caso de la indicación geográfica.

\footnotetext{
${ }^{15}$ En la estructura de la OMC se incluyen una serie de Anexos de carácter sectorial para la regulación de ciertos aspectos del comercio. Entre estos Anexos es de destacarse para nuestra materia el 1.C que incorpora el Acuerdo sobre los Aspectos de los Derechos de Propiedad Intelectual relacionados con el Comercio (ADPIC en castellano o TRIPS en inglés). El Acuerdo ADPIC tiene como novedad que incluye los procedimientos y resoluciones de carácter penal que han de aplicarse para los casos de falsificación dolosa de marcas y de usurpación dolosa de derechos de autor. Lo anterior en virtud de la obligación mínima que se establece a los miembros dentro del Acuerdo. Asimismo, entre las posibles sanciones se encuentran: penas de prisión y sanciones pecuniarias, que cumplen una función disuasoria. Igualmente se establecen como medidas coadyuvantes de este proceso la confiscación de la mercancía y sus accesorios, su decomiso y destrucción.
} 
De esta forma tenemos que dentro del artículo 24 de los ADPIC, se consagra lo que se ha denominado las cláusulas del Abuelo ${ }^{16}$. Esto es, limitaciones a la protección por los usos que se hayan hecho en el pasado, puesto que se establece que no se puede impedir el uso de una indicación geográfica cuando se ha hecho con anterioridad al 15 de abril de 1994, si este uso ha durado más de 10 años o incluso por menos si se hace de buena fe. Algo similar establece respecto de las marcas que se identifiquen con indicación geográfica y que se han registrado o se han usado de buena fe (Abarza \& Katz, 2002, pág. 27).

Así, si nos atenemos a lo anterior, todo reclamo que pudieran realizar a México y sus productores, por parte de la Unión Europea (UE), tal y como es la lista que ha sido enviada con la finalidad de verificar los productos que desean incluir en las denominadas indicaciones geográficas, pudiera ser rechazada en función de la cláusula del Abuelo, si es que realmente existe un interés formal de nuestros responsables políticos y económicos de salvaguardar los intereses nacionales.

\subsubsection{La llamada "Guerra de los quesos".}

Este curioso nombre es con el que la prensa ha bautizado las pretensiones de la Unión Europea en materia de protección (¿o podríamos llamarlo sobreprotección?) de sus productos sin tomar en consideración las reglas mínimas y esenciales en materia de lo que de forma doctrinaria se establece sobre la indicación geográfica, y por lo visto, menos aún a lo que se refiere a la Cláusula del Abuelo de los convenios de los ADPIC, así, la prensa explica:

Cerca de 300 productos se encuentran en la lista de la llamada "Guerra de los Quesos", con la cual productos reconocidos como el queso parmesano, manchego o gruyere producidos fuera de la ciudad donde se crearon no podrán ser vendidos bajo ese mismo nombre. Con esto, compañías nacionales como Lala y Alpura no podrían producir estos productos y venderlos con el nombre por el que ya son reconocidos...Lo que se busca en México es que se reconozca la indicación geográfica del producto, pero además se le incluya un apellido que especifique que este producto es de este lugar. Así el queso manchego original se llamaría "queso manchego de la mancha" y el regular producido en México u otras regiones sería simplemente manchego (MundoHispanico, 2017).

Si Europa triunfa en su intención de que México reconozca estas indicaciones, que incluyen embutidos y vinos, los consumidores mexicanos ya no podrán comer queso manchego, gruyere, ni parmesano que no esté hecho en las regiones europeas donde se originaron, ... La solución que empresarios del sector buscan en México es que se reconozca esta indicación con "nombre y apellido", es decir

\footnotetext{
${ }^{16}$ El Protocolo de Aplicación Provisional del GATT, contenían una grandfather clause (cláusula del abuelo), en virtud de la cual los Estados parte se comprometían a aplicar la Parte II (artículos III a XXIII) "en todo lo que sea compatible con su legislación en vigor" en la fecha del protocolo respectivo. Vid., Infra (Witker \& Hernández, Régimen Jurídico del comercio exterior de México, 2002, pág. 83)
} 
que sólo los productores de la UE puedan vender productos bajo el nombre de "queso manchego de la Mancha" y que los demás lo hagan bajo el nombre de "queso tipo manchego", como se comercializa actualmente (Villamil, 2017).

Con esto se pretende dejar en claro varias cosas, lo primero, el desconocimiento en materia de propiedad industrial al confundir los conceptos de indicación geográfica y denominación de origen, segundo, el desconocimiento respecto a la llamada Cláusula del Abuelo en materia del GATT / ADPIC a la cual México podría acogerse demostrando un uso de buena fe mayor a 10 años y no pretender negociar necedades de la Unión Europea.

En última instancia, si la Unión Europea pretende hacer una autentica protección de sus indicaciones geográficas, debiera de ser de los países miembros de la Unión de Lisboa que a fecha de 13 de octubre de 2017 y según datos de la Organización Mundial de la Propiedad Intelectual (OMPI), son los siguientes:

\begin{tabular}{|c|c|c|c|}
\hline \multirow{3}{*}{$\begin{array}{l}\text { State } \\
\text { Algeria }\end{array}$} & \multicolumn{2}{|c|}{$\begin{array}{r}\text { at (1958), revised at Stockholm (196 } \\
\text { (Lisbon Union) } \\
\text { Status October 13, } 2017\end{array}$} & $\begin{array}{l}\text { n } 1979 \\
\text { Agreement to which }\end{array}$ \\
\hline & \multirow{2}{*}{$\begin{array}{l}\text { Date on which State } \\
\text { became party to the } \\
\text { Agreement } \\
\text { July } 5,1972\end{array}$} & \multicolumn{2}{|c|}{$\begin{array}{l}\text { Latest Act of the Agreement to which } \\
\text { State is party and date on which it } \\
\text { became party to Act }\end{array}$} \\
\hline & & Stockholm: & October 31,1973 \\
\hline Bosnia and Herzegovina & July 4,2013 & Stockholm: & July 4, 2013 \\
\hline Bulgaria & August 12,1975 & Stockholm: & August 12,1975 \\
\hline $\begin{array}{l}\text { Burkina Faso } \\
\text { Congo }\end{array}$ & $\begin{array}{l}\text { September } 2,1975 \\
\text { November } 16,1977\end{array}$ & $\begin{array}{l}\text { Stockholm: } \\
\text { Stockholm: }\end{array}$ & $\begin{array}{l}\text { September } 2,1975 \\
\text { November } 16,1977\end{array}$ \\
\hline Costa Rica. & July 30,1997 & Stockholm: & July 30,1997 \\
\hline Cuba & September 25,1966 & Stockholm: & April 8, 1975 \\
\hline Czech Republic. & January 1, 1993 & Stockholm: & January 1,1993 \\
\hline Democratic People's Republic of Korea......... & January 4,2005 & Stockholm & January 4,2005 \\
\hline France $^{1}$ & September 25,1966 & Stockholm: & August 12,1975 \\
\hline Gabon & June 10,1975 & Stockholm: & June 10,1975 \\
\hline Georgia & September 23, 2004 & Stockholm & September 23,2004 \\
\hline Haiti & September 25,1966 & Lisbon: & September 25,1966 \\
\hline 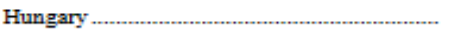 & March 23, 1967 & Stockholm: & October 31,1973 \\
\hline Iran (Islamic Republic of) & March 9, 2006 & Stockholm: & March 9,2006 \\
\hline Israel ... & September 25,1966 & Stockholm: & October 31,1973 \\
\hline Italy & December 29,1968 & Stockholm: & April 24, 1977 \\
\hline Mexico & September 25,1966 & Stockholm: & January 26,2001 \\
\hline Montenegro & June 3,2006 & Stockholm: & June 3,2006 \\
\hline Nicaragua & June 15,2006 & Stockholm & June 15,2006 \\
\hline Peru. & May 16,2005 & Stockholm: & May 16,2005 \\
\hline Portugal ......... & September 25, 1966 & Stockholm: & April 17, 1991 \\
\hline Republic of Moldova & April 5, 2001 & Stockholm: & April 5, 2001 \\
\hline Serbia $^{2}$ & June 1,1999 & Stockholm: & June 1,1999 \\
\hline Slovakia & January 1,1993 & Stockholm: & January 1,1993 \\
\hline $\begin{array}{l}\text { The former Yugoslav Republic of Macedonia } \\
\text { Togo.. }\end{array}$ & $\begin{array}{l}\text { October } 6,2010 \\
\text { April } 30,1975\end{array}$ & $\begin{array}{l}\text { Stockholm: } \\
\text { Stockholm: }\end{array}$ & $\begin{array}{l}\text { October } 6,2010 \\
\text { April } 30,1975\end{array}$ \\
\hline Tunisia & October 31,1973 & Stockholm: & October 31,1973 \\
\hline
\end{tabular}

\footnotetext{
${ }^{2}$ Including all Overseas Departments and Territories

2 Serbia is the continuing State from Serbia and Montenegro as from June 3.2006.
}

Fuente: (World Intellectual Poperty Organization (WIPO), 2017) 
Así, Francia e Italia sería la única que podría presentar quejas en cuanto a la violación de una denominación de origen, si es que también su producto se encuentra registrado como tal y cuenta con su Consejo Regulador, más no España, quien no figura como miembro de la Unión de Lisboa. De hecho, México si tiene una queja formal por el uso del nombre "Tequila" con Heineken porque la cerveza holandesa "Desperados" quien ostenta dicho sabor ${ }^{17}$ o que contiene "Tequila"18 , esto es así puesto que el andamiaje legal que sustenta la denominación de Tequila señala de manera clara y concisa a que llamarle así, y no únicamente a la casualidad de que dicho producto sea realizado en una zona geográfica determinada.

Siendo, por tanto, las siguientes listas las únicas que podrían tener un fundamento legal por parte de estos países.

\begin{tabular}{|l|l|l|}
\hline Francia & Abondance $\left(^{*}\right)$ & Queso \\
\hline Francia & Ail blanc de Lomagne & Ajo \\
\hline Francia & Ail de la Drôme & Ajo \\
\hline Francia & Ail rose de Lautrec & Ajo \\
\hline Francia & Beaufort $\left(^{*}\right)$ & Queso \\
\hline Francia & Bleu d'Auvergne $\left(^{*}\right)$ & Queso azul de vaca \\
\hline Francia & Brie de Meaux $(*)$ & Queso suave de vaca \\
\hline Francia & $\begin{array}{l}\text { Camembert de } \\
\text { Normandie }\left(^{*}\right)\end{array}$ & Queso suave de vaca \\
\hline Francia & $\begin{array}{l}\text { Canard à foie gras du } \\
\text { Sud-Ouest }(\text { Chalosse, } \\
\text { Gascogne, Gers, Landes, } \\
\text { Périgord, Quercy) }\end{array}$ & $\begin{array}{l}\text { Otras carnes cocidas e } \\
\text { hígado fresco }\end{array}$ \\
\hline Francia & $\begin{array}{l}\text { Cantal / fourme de Cantal } \\
\text { / cantalet }(*)\end{array}$ & Queso duro de vaca \\
\hline Francia & Chabichou du Poitou $(*)$ & Queso \\
\hline Francia & Comté $(*)$ & Queso duro de vaca \\
\hline Francia & $\begin{array}{l}\text { Crottin de Chavignol / } \\
\text { Chavignol }(*)\end{array}$ & Queso \\
\hline Francia & Emmental de Savoie & Queso duro de vaca \\
\hline Francia & Époisses $(*)$ & Queso \\
\hline Francia & Fourme d'Ambert $(*)$ & Queso \\
\hline Francia & Gruyère & Queso duro de vaca \\
\hline Francia & $\begin{array}{l}\text { Huile d'olive de Haute- } \\
\text { Provence }\end{array}$ & Aceite de oliva \\
\hline
\end{tabular}

${ }^{17}$ Para mayor información se pueden consultar: http://www.milenio.com/negocios/heineken-desperadosdemanda-crt-cerveza-tequila $0 \_980901920 . \mathrm{html}$ y https://munchies.vice.com/es/article/pay $7 \mathrm{vv} /$ por-que-elconsejo-regulador-del-tequila-podria-demandar-a-heineken

${ }^{18}$ Esto según la interpretación que se le desee dar a la palabra "saborizada". 


\begin{tabular}{|l|l|l|}
\hline Francia & $\begin{array}{l}\text { Huile essentielle de } \\
\text { lavande de Haute- } \\
\text { Provence / Essence de } \\
\text { lavande de Haute- } \\
\text { Provence }(*)\end{array}$ & Esencias de aceite \\
\hline Francia & Huîtres Marennes Oléron & Moluscos no procesados \\
\hline Francia & Jambon de Bayonne & Jamón de cerdo \\
\hline Francia & Lentille verte du Puy & Lentejas \\
\hline Francia & Maroilles / Marolles $\left(^{*}\right)$ & Queso \\
\hline Francia & Morbier & Queso \\
\hline Francia & $\begin{array}{l}\text { Munster }(*) ; \text { Munster- } \\
\text { Géromé }(*)\end{array}$ & Queso suave de vaca \\
\hline Francia & Neufchâtel & Queso \\
\hline Francia & Noix de Grenoble $(*)$ & Nueces \\
\hline Francia & $\begin{array}{l}\text { Piment } \text { d'Espelette } ; \\
\text { Piment }\end{array}$ & Pimienta \\
\hline
\end{tabular}

\begin{tabular}{|c|c|c|}
\hline Italia & $\begin{array}{l}\text { Aceto Balsamico di } \\
\text { Modena }(*)\end{array}$ & Vinagre \\
\hline Italia & $\begin{array}{l}\text { Aceto balsamico } \\
\text { tradizionale di Modena }\end{array}$ & Vinagre \\
\hline Italia & Aprutino Pescarese & Aceite de oliva \\
\hline Italia & Asiago $(* *)$ & Queso duro de vaca \\
\hline Italia & Bresaola della Valtellina & Otras carnes curadas \\
\hline Italia & Capocollo di Calabria & Carne curada \\
\hline Italia & Сорра di Parma & Carne curada \\
\hline Italia & Cotechino Modena $(*)$ & $\begin{array}{l}\text { Preparaciones de carne de } \\
\text { cerdo }(100 \%)\end{array}$ \\
\hline Italia & Culatello di Zibello $(*)$ & Otras carnes curadas \\
\hline Italia & Fontina $(*)$ & Queso duro de vaca \\
\hline Italia & Gorgonzola (**) & Queso azul de vaca \\
\hline Italia & Grana Padano $(*)$ & Queso duro de vaca \\
\hline Italia & $\begin{array}{l}\text { Mela Alto Adige; } \\
\text { Südtiroler Apfel (*) }\end{array}$ & Manzanas \\
\hline Italia & Mortadella Bologna & $\begin{array}{l}\text { Preparaciones de carne de } \\
\text { cerdo }(100 \%)\end{array}$ \\
\hline Italia & $\begin{array}{l}\text { Mozzarella di Bufala } \\
\text { Campana }(*)\end{array}$ & $\begin{array}{l}\text { Queso blando de (buffalo- } \\
\text { bufflone) de Búfalo. }\end{array}$ \\
\hline Italia & Pancetta di Calabria $(*)$ & Carne curada \\
\hline Italia & Parmigiano Reggiano (*) & Queso duro de vaca \\
\hline Italia & Pecorino Romano $(*)$ & Queso duro de oveja \\
\hline Italia & $\begin{array}{l}\text { Piadina Romagnola / } \\
\text { Piada Romagnola }\end{array}$ & Otro pan \\
\hline
\end{tabular}




\begin{tabular}{|c|c|c|}
\hline Italia & $\begin{array}{l}\text { Pomodoro S. Marzano } \\
\text { dell'Agro Sarnese- } \\
\text { Nocerino }(*)\end{array}$ & Tomates \\
\hline Italia & Prosciutto di Parma & Jamón de cerdo \\
\hline Italia & Prosciutto di San Daniele & Jamón de cerdo \\
\hline Italia & Prosciutto Toscano $(*)$ & Jamón de cerdo \\
\hline Italia & Provolone Valpadana $(*)$ & Queso suave de vaca \\
\hline Italia & Riso del Delta del Po & Arroz \\
\hline Italia & $\begin{array}{l}\text { Salamini italiani alla } \\
\text { cacciatora }(*)\end{array}$ & Otras carnes curadas \\
\hline Italia & Salsiccia di Calabria & Carne curada \\
\hline Italia & Soppressata di Calabria & Otras carnes curadas \\
\hline Italia & $\begin{array}{l}\text { Speck Alto Adige / } \\
\text { Südtiroler Markenspeck / } \\
\text { Südtiroler Speck }(*)\end{array}$ & Jamón de cerdo \\
\hline Italia & Taleggio $(*)$ & Queso suave de vaca \\
\hline Italia & Toscano $(*)$ & Aceite de oliva \\
\hline Italia & Zampone Modena (*) & $\begin{array}{l}\text { Preparaciones de carne de } \\
\text { cerdo }(100 \%)\end{array}$ \\
\hline Italia & $\begin{array}{l}\text { Alto Adige / Südtirol / } \\
\text { Südtiroler / dell'Alto } \\
\text { Adige }(*)\end{array}$ & Vino \\
\hline Italia & Asti & Vino \\
\hline Italia & Barbaresco $(*)$ & Vino \\
\hline Italia & Barbera d'Alba & Vino \\
\hline Italia & Barbera d'Asti & Vino \\
\hline Italia & Bardolino (*) & Vino \\
\hline Italia & Barolo (*) & Vino \\
\hline Italia & Brachetto d'Acqui / Acqui & Vino \\
\hline Italia & Brunello di Montalcino $(*)$ & Vino \\
\hline Italia & Chianti $(*)$ & Vino \\
\hline Italia & Chianti Classico $(*)$ & Vino \\
\hline Italia & $\begin{array}{l}\text { Conegliano - Prosecco / } \\
\text { Conegliano } \\
\text { Valdobbiadene - Prosecco } \\
\text { / Valdobbiadene - } \\
\text { Prosecco }\end{array}$ & Vino \\
\hline Italia & Dolcetto d'Alba & Vino \\
\hline Italia & Emilia / dell'Emilia & Vino \\
\hline Italia & Franciacorta & Vino \\
\hline Italia & Lambrusco di Sorbara $(*)$ & Vino \\
\hline Italia & $\begin{array}{l}\text { Lambrusco Grasparossa di } \\
\text { Castelvetro }(*)\end{array}$ & Vino \\
\hline Italia & Marca Trevigiana & Vino \\
\hline Italia & Marsala & Vino \\
\hline
\end{tabular}




\begin{tabular}{|l|l|l|}
\hline Italia & $\begin{array}{l}\text { Montepulciano d'Abruzzo } \\
(*)\end{array}$ & Vino \\
\hline Italia & Oltrepò Pavese & Vino \\
\hline Italia & Prosecco $(*)$ & Vino \\
\hline Italia & Rubicone & Vino \\
\hline Italia & Salento & Vino \\
\hline Italia & Sicilia & Vino \\
\hline Italia & Soave $\left(^{*}\right)$ & Vino \\
\hline Italia & Toscana / Toscano & Vino \\
\hline Italia & Trento & Vino \\
\hline Italia & Valpolicella $(*)$ & Vino \\
\hline Italia & Veneto & Vino \\
\hline Italia & $\begin{array}{l}\text { Vernaccia di San } \\
\text { Gimignano }\end{array}$ & Vino \\
\hline Italia & $\begin{array}{l}\text { Vino Nobile di } \\
\text { Montepulciano }\end{array}$ & Vino \\
\hline
\end{tabular}

Lista tomada del Aviso por el cual se dan a conocer y se somete a consulta las indicaciones geográficas que la Unión Europea busca proteger en el territorio de los Estados Unidos Mexicanos en el marco de las negociaciones de la modernización del Acuerdo de Asociación Económica, Concertación Política y Cooperación entre los Estados Unidos Mexicanos, por una parte, y la Comunidad Europea y sus Estados Miembros, por otra. Fuente, Secretaría de Economía.

\subsubsection{Los antecedentes de esta batalla y la jurisprudencia mexicana.}

Resulta revelador el hecho de que si se analiza la jurisprudencia en México en torno a esta cuestión se pueden localizar dos muy importantes en torno a esto, una es la que a la letra expresa:

Se consideran marcas colectivas, de conformidad con el Convenio de París para la Protección de la Propiedad Industrial y la Ley de la Propiedad Industrial, aquellos signos visibles que distingan productos o servicios de una asociación o sociedad de productores, de otros de su misma especie o clase en el mercado, cuyo objeto sea destacar el origen geográfico, material, modo de fabricación u otras características comunes de los bienes y servicios que se pretenden amparar y que se utilizan, generalmente, para promocionar productos o servicios característicos de una región, generando un marco de cooperación entre los productores e impulsando su comercialización dentro y fuera del país de origen. Por otro lado, el artículo 98 de la citada ley establece expresamente que las marcas colectivas se regirán, en lo que no haya disposición especial, por lo establecido en el propio ordenamiento para las marcas ordinarias, precepto que resulta acorde con el numeral 2) del artículo 7 bis del señalado instrumento internacional que faculta a 
los Estados firmantes para decidir sobre las condiciones particulares bajo las cuales una marca colectiva ha de ser protegida, de manera que su análisis debe seguirse del mismo modo que el de las marcas ordinarias, por lo que a efecto de determinar la procedencia de su registro, debe atenderse a la fracción IV del artículo 90 de la Ley de la Propiedad Industrial, para evitar que sean registrados signos descriptivos que se limiten a ofrecer información acerca de los productos y servicios que se pretenden proteger. Aunado a ello, existe una excepción consistente en que una marca colectiva puede contener términos geográficos, siempre y cuando no esté conformada exclusivamente por ese indicativo, sino que debe acompañarse de otro signo susceptible de registro por sí mismo; esto es, una denominación de marca colectiva que contenga una indicación geográfica será registrable únicamente si se conforma, a su vez, por otro vocablo que le otorgue distintividad suficiente para su registro ${ }^{19}$.

La importancia que reviste esta jurisprudencia radica en el hecho de que se señala la posibilidad de equiparar la marca colectiva con una indicación geográfica, esto es así puesto que el famoso slogan "Hecho en México" no es una indicación geográfica, es una marca colectiva que reviste el hecho de que se trata de un producto fabricado en nuestro país. De esta forma una posible salida negociada y menos traumática, sería permitir que estos productos se registren como marcas colectivas.

Aún más reveladora resulta la siguiente jurisprudencia, la cual a la letra señala:

El requisito de procedibilidad contenido en el artículo 229 de la Ley de la Propiedad Industrial para ejercer acciones civiles y penales, o para adoptar las medidas previstas en el diverso 199 Bis de dicha Ley consistente en que el interesado demuestre que hizo del conocimiento público el derecho de propiedad industrial del que es titular, aplicando a los productos alguna leyenda o signo distintivo conforme a los numerales 26 y 131 del propio ordenamiento (relativos a patentes y marcas, respectivamente), no se refiere a la figura de la denominación de origen. Ello es así, porque tanto el Arreglo de Lisboa relativo a la Protección de las Denominaciones de Origen y su Registro Internacional como la Ley de la Propiedad Industrial, coinciden en que la forma en que debe hacerse del conocimiento de terceros que se emitió declaración de una denominación de origen, es a través de su publicación en un medio oficial de difusión, ya sea en el Diario Oficial de la Federación, en el caso del Estado mexicano, o en el periódico oficial de la Oficina Internacional de la Organización Mundial de la Propiedad Intelectual (OMPI), en el caso de denominaciones extranjeras. Es decir, el conocimiento público de la existencia de una denominación es diferente a la forma en que se publicita que se es titular de una patente o marca, pues la titularidad del

${ }^{19}$ Esta tesis aparece bajo el rubro: MARCAS COLECTIVAS. SU NOCIÓN Y FACTORES A CONSIDERAR PARA DETERMINAR LA PROCEDENCIA DEL REGISTRO DE LAS QUE CONTENGAN UNA INDICACIÓN GEOGRÁFICA. Décima Época, Tribunales Colegiados de Circuito, Tesis Aislada, Semanario Judicial de la Federación y su Gaceta, Libro III, diciembre de 2011, Tomo 5, Materia Administrativa, Tesis: I.4o.A.804 A (9a.) Página: 3785. Amparo directo 334/2011. Asociación Nacional de Fabricantes de Alcoholes y Licores. 29 de septiembre de 2011. Unanimidad de votos. Ponente: Jesús Antonio Nazar Sevilla. Secretaria: Indira Martínez Fernández. 
derecho no pertenece a un individuo, sino al Estado que tiene registrada una denominación ante la Organización Mundial referida. Por tanto, el artículo 229 de la Ley relativa no contraviene el principio de supremacía constitucional contenido en el artículo 133 de la Constitución Política de los Estados Unidos Mexicanos, al no imponer mayores requisitos para la adopción de medidas para la defensa de las denominaciones de origen que los establecidos en el Arreglo de Lisboa para la Protección de dicha figura, al no referirse a la misma materia ${ }^{20}$.

De esta jurisprudencia, se puede apreciar entre líneas los intentos de parte de productores europeos de iniciar procedimientos civiles en contra de productores nacionales, en este caso quien lo intento fue el Consorzio del Formaggio Parmigiano Reggiano, es decir, productores de queso de Parma, los cuales al intentar un procedimiento, se toparon con la negativa de su acción en virtud de que no pudieron acreditar la supuesta violación, ya que como se desprende de esta lectura, una cosa son marcas y otra muy diferente la Denominación de Origen.

\section{CONCLUSIONES}

Primera. Se puede señalar, por lo visto anteriormente, que las negociaciones iniciadas por México contaban con un amplio aval del gobierno y dos aliados europeos, España y Alemania, más no con un amplio consenso del resto de países de la Unión Europea, puesto que se presentaron varias cuestiones de carácter técnico-jurídico que pretendieron hacer fracasar las negociaciones, entre ellas la del Dialogo Político o la llamada "Clausula Democrática” lo que demuestra la apatía hacia nuestro país.

Segunda. De lo revisado en esta investigación puede resaltarse el hecho de que desde los inicios de la negociación del TLCUEM, en materia de propiedad intelectual, las firmas, adhesiones y ratificaciones que nuestro país debió hacer para satisfacer los niveles de exigencia que solicitaban sus contrapartes europeas, fueron de carácter exhaustivo.

Tercera. En la renegociación del Acuerdo, y tal como lo hace ver la Secretaria de Economía, existe un interés especial en que México ceda a proteger determinados nombres de

\footnotetext{
${ }^{20}$ Esta jurisprudencia aparece bajo el rubro de: PROPIEDAD INDUSTRIAL. EL ARTÍCULO 229 DE LA LEY RELATIVA NO CONTRAVIENE EL PRINCIPIO DE SUPREMACÍA CONSTITUCIONAL. Novena Época, Registro: 164262, Primera Sala, Tesis Aislada, Semanario Judicial de la Federación y su Gaceta, Tomo XXXII, julio de 2010, Materia Administrativa, Constitucional, Tesis: 1a. XCVI/2010, Página: 255, Amparo en revisión 2110/2009. Consorzio del Formaggio Parmigiano Reggiano. 24 de marzo de 2010. Unanimidad de cuatro votos. Ausente: José de Jesús Gudiño Pelayo. Ponente: Olga Sánchez Cordero de García Villegas. Secretaria: Rosalía Argumosa López.
} 
productos fabricados bajo la figura de la indicación geográfica, la cual es en sí misma una figura de carácter atípico.

Cuarta. Dentro de la lista, antes mencionada, existen países que no figuran dentro del Acuerdo de Lisboa en materia de denominación de Origen, figura que sí reconoce nuestro país y a la cual pertenece desde la década de los sesenta, con un producto estrella, el Tequila, siendo claro que los únicos países que pudieran reclamar a México, y si y solo si, tuvieran sus productos bajo esta denominación serian Francia e Italia.

Quinta. Aun en el supuesto de que la Unión Europea exigiera la protección de manera autoritaria y sin una legitimidad jurídica, México puede muy bien invocar la Cláusula del Abuelo en el marco de los Acuerdos TRIPS, la cual permitiría que, si un nombre se ha utilizado de buena fe por más de 10 años, no se le puede exigir una protección, tal y como sería el caso de los quesos manchego, como principal beneficiado de esto.

Sexta. De lo visto, desde el punto de vista de la jurisprudencia, se pudo observar como desde la perspectiva legal se pudieron dar opciones para la Unión Europea, uno es la llamada marca colectiva, la cual permitiría el registro de una región geográfica como marca, tal y como es el caso de la llamada marca "Hecho en México".

Séptima. Otro caso que da muestras de que ya se ha intentado reclamar derechos por violaciones a la Propiedad Industrial es el caso de reclamación que en su momento hizo el Consorzio del Formaggio Parmigiano Reggiano, el cual no pudo acreditar un derecho sobre la indicación "Parma", puesto que esta figura no existe como tal en nuestro país.

Octava. En realidad, para México podría resultar fácil, desde una perspectiva jurídica, evitar complacer a sus socios europeos, y salvaguardar con esto a su industria nacional, puesto que no hay que olvidar que la asimilación que hace el consumidor a un nombre determinado genera la idea preconcebida de calidad lo que lo lleva a repetir la experiencia de la compra, con la cual genera una lealtad cliente, nombre y marca, que en términos absolutos es dinero que perciben las empresas. Ahora bien, el permitir las exigencias europeas, podría llevar a que muchos productores pierdan competitividad, clientes y, por ende, dinero y se vea afectada una industria nacional valuada en millones de pesos mexicanos. La cuestión resulta entonces un único tipo, de voluntad política, en el afán de proteger nuestra industria, puesto que sería absurdo pensar que nuestras autoridades cedieran en este tipo de cuestiones de manera unilateral en una especie de rendición tacita a las negociaciones. 


\section{BIBLIOGRAFÍA}

Abarza, J., \& Katz, J. (2002). Los derechos de la propiedad intelectual en el mundo de la $O M C$. Santiago de Chile: CEPAL/ECLAC Naciones Unidas.

Appel, M. (2 de junio de 2005). México-UE:De la apatía a la consideración. Proceso.

Aranda Godoy, A. M. (marzo de 2001). Las dificultades de integrar un sistema jurídico de Estado y otro de Mercado Común, en un Acuerdo de Libre Comercio: El TLCUEMM". Revista Mexicana de Derecho Internacional Privado(9).

Cruz Miramontes, R. (2003). Las relaciones comerciales multilaterales de México y el Tratado de Libre Comercio con la Unión Europea. México: Instuto de Investigaciones Jurídicas de la UNAM; Universidad Iberoamericana.

Cuenca García, E. (2002). Europa e Iberoamérica. Madrid: Síntesis.

Mansilla y Mejía, M. E. (noviembre de 2001). El Acuerdo de Asociación Económica, Concertación Política y Cooperación entre los Estados Unidos Mexicanos y la Comunidad Europea y sus Estados Miembro, y la solución de controversias. Revista Mexicana de Derecho Internacional Privado(10).

MundoHispanico. (julio de 2017). MundoHispanico. Recuperado el 28 de octubre de 2017, de Guerra de los quesos entre México y la Unión Europea: https://mundohispanico.com/sabor/guerra-de-los-quesos

Peña, F., \& Torrent, R. (2005). Hacia una nueva etapa en las relaciones Unión Europea América Latina. Barcelona: Publicaciones y ediciones de la Universidad de Barcelona.

Sberro, S. (2004). El Tratado de Libre Comercio con la Unión Europea: ¿secuela del TLCAN o alternativa estratégica? En G. A. De la Reza, México más allá del TLCAN. Competitividad y diversificación de mercados. México: Universidad Autonoma Metropolitana, Plaza y Valdés Editores.

Secretaría de Economía. (14 de agosto de 2017). Gobierno de la República, Secretaría de Economía. Recuperado el 23 de octubre de 2017, de Consulta sobre Indicaciones Geográficas en el marco de la Modernización del TLCUEM: https://www.gob.mx/se/acciones-yprogramas/consulta-sobre-indicaciones-geograficas-en-el-marco-de-la-modernizacion-deltlcuem

Villamil, V. (14 de agosto de 2017). El Financiero. Recuperado el 28 de octubre de 2017, de Economia - México está 'en guerra' con Europa por el queso manchego: 
http://www.elfinanciero.com.mx/economia/mexico-esta-en-guerra-con-europa-por-el-quesomanchego.html

Witker, J., \& Hernández, L. (2002). Régimen Jurídico del comercio exterior de México. México: Instituto de Investigaciones Jurídicas de la UNAM.

Witker, J., \& Hernández, L. (2002). Régimen Jurídico del comercio exterior en México (Segunda ed.). México: Instituto de Investigaciones Jurídicas UNAM.

World Intellectual Poperty Organization (WIPO). (13 de octubre de 2017). Lisbon Agreement for the Protection of Appellations of Origin and their International Registration Lisbon Agreement (1958), revised at Stockholm (1967), and amended in 1979 (Lisbon Union) Status October 13, 2017. Recuperado el 23 de octubre de 2017, de Lisbon Agreement WIPO: http://www.wipo.int/export/sites/www/treaties/en/documents/pdf/lisbon.pdf

Trabalho recebido em 22 de outubro de 2019

Aceito em 01 de junho de 2020 